Esto solo es posible cuando se deposita la confianza exclusivamente en Cristo, salvador del hombre y luz de las naciones.

Felicitamos a los autores de esta monografía por su empeño por dar reconocimiento al jesuita Pedro Páez, cuya trayectoria ojalá generara más publicaciones que resaltaran su extraordinaria dimensión humana y creyente. Su figura no solo entraña la de un adalid de su tiempo sino también la de una brújula que no deja de guiar al pueblo de Dios en la hora presente. Pero es justo congratularse asimismo con la Fundación PalArq, con la Embajada de España en Etiopía y con la Agencia Española de Cooperación Internacional para el Desarrollo (AECID), que de diversas maneras han puesto y ponen su granito de arena para repristinar la talla humana, cultural y espiritual de Páez.

Concluyendo, y sumándome al parecer de la embajadora de la Peña, este volumen aclara documentalmente algunos puntos de la vida del padre Páez, a la vez que facilita y estimula el conocimiento de su formidable apostolado. Son páginas que encumbran y resaltan la valía de "este descubridor jesuita español, importante personalidad de nuestra cultura e historia" (pág. 12). Anhelamos que la abnegación de este religioso sirva de paradigma y modelo para las nuevas generaciones y las lleve a apostar por la excelencia, la altura de miras y la hondura de planteamientos. Antaño como hogaño, la vida de Pedro Páez es una antorcha que nos aleja del gris en el que no pocas veces nos instalamos, disipando insensibilidades y egoísmos.

Esta publicación, en definitiva, puede convertirse en una sonora llamada, en un aguijón que nos espolee para que el talante de Pedro Páez y de aquellos otros germinales jesuitas no quede enclaustrado en un pasado remoto ni nos deje indiferentes. Antes bien ha de edificarnos y animarnos a salir de nosotros mismos para abandonar mediocridades, crecer por dentro, optar por la innovación y transitar, en fin, por los caminos del Evangelio, hontanar de esperanza para el hombre y semilla de dignidad para los pueblos.

Fernando Chica Arellano

Observador Permanente de la Santa Sede ante la FAO, el FIDA, y el PMA arellano@libero.it

\title{
José Granados - Juan Antonio Granados - Carlos Granados, ¿Tendrán fe nuestros hijos? Educar desde la vida sacramental, Madrid, Didáskalos, 2019, 144 pp., $18 €$.
}

https://doi.org/10.46543/ISID.2029.1015

Vivimos tiempos arduos para la educación. Las aulas se han convertido en terreno de un juego político en el que los cambios continuos de leyes 
testimonian una perturbación y una confusión en el seno de la sociedad. Por ello, plantear la cuestión que presenta este libro, podría parecer casi una osada provocación: ¿educar desde la vida sacramental? ¿Es este un horizonte adecuado, que se puede proponer al mundo como camino para el acto educativo? ¿Qué se entiende aquí cuando se dice "Educar desde la vida sacramental"?

La cuestión que plantean los autores en los capítulos de este interesante libro no es la de una educación para los sacramentos (aunque no se excluye). La cuestión es cómo educar desde la lógica sacramental. Por "lógica sacramental" entienden el modo de ver la creación, las personas, las relaciones, el cuerpo, que se ha introducido a partir de la encarnación. La encarnación supone dar un nuevo valor a lo creado. El pan, el vino, el agua, pero también el perdón, el matrimonio, la enfermedad, se convierten ahora en lugares para la acción de Dios. El cuerpo es ese lugar sacramental por excelencia, a partir de la encarnación.

¿Qué significa una educación que parte de este principio? Nos lo explica en primer lugar José Granados, en dos capítulos realmente sabrosos, titulados: “Tendrán fe nuestros hijos? Dios en la educación" (pp. 23-54) y "La educación sacramental: palabras, afectos, prácticas" (pp. 55-78). La visión del acto educativo que aquí se presenta trata de rebasar la concepción utilitarista. Educar no es preparar para poder hacer bien otra cosa, que vendrá luego, y que normalmente se piensa que es la incorporación al mundo laboral. Pues entonces es como si la educación no fuera ya vida, y la verdadera vida viniera luego. Al contrario, educar es participar en la vida. Por eso la educación tendría sentido realizarla aun cuando se supiera que el niño, por ejemplo, debido a una enfermedad, no fuera a llegar luego a la edad adulta. Es decir, en la educación se comunica la experiencia de la vida buena.Y así se puede después juzgar sobre el bien al que sirven las distintas actividades que realizaremos en la sociedad. Otra forma de decirlo: en la educación no solo se nos dan los medios para cumplir nuestros deseos, sino que se generan nuestros deseos, para que apunten a una vida plena, noble, digna y grande.

¿Y no nos hablan de esto los sacramentos? ¿No son momentos en que nuestros deseos, incorporados al cuerpo de Jesús, reciben otra dimensión? Los sacramentos, entonces, nos recuerdan lo que es la educación, nos dicen que toda la educación, en cuanto introduce en el arte de vivir, es educación sacramental.

A continuación, Carlos Granados, en una valiosa contribución titulada: "Enseñar a ver: la educación del ojo" (pp. 79-98) y en otra: "Formar, adiestrar, instruir, ¿qué es educar?" (pp. 119-140), trata de adentrarse en la novedad de la pedagogía cristiana, que pasa, precisamente, a través de la novedad de Jesús y de la encarnación. Una pedagogía cristiana es 
sacramental por naturaleza; por ello enseña a ver las cosas de un modo nuevo; y por la misma razón supera el ámbito del "adiestramiento", que consiste en entender la educación solo como el arte de aprender un oficio, y traspasa también el ámbito de la"instrucción", que es comprender la educación solo como transmisión de conocimientos, para adentrarse en el ámbito de la "formación". En este sentido, educar es enseñar el arte de vivir. Así, el maestro se convierte también en testigo de un modo de vida, de una manera de afrontar las relaciones y los vínculos en la sociedad.

Por último, Juan Antonio Granados, en un capítulo titulado: "Sentido del honor, despertar a la grandeza de un bien común" (pp. 99-118), acierta a mostrar el sentido del "bien común" en una pedagogía que ya no mira solo a la suma de bienes particulares, o a compartir bienes materiales, sino a generar el sentido fuerte de comunión en el bien, que es propio del "bien común". Esta educación asumirá también de un modo nuevo el sentido del "honor", que en toda la historia de la educación ha jugado un papel decisivo y que hoy es necesario retomar a la luz del"bien común".

Finalmente, debo mencionar con satisfacción el original prólogo que Gregorio Luri ha escrito para este precioso volumen en un estilo de "confesión pública", como él lo titula. Este pensador, filósofo y pedagogo muestra, junto a su erudición, una magnífica clarividencia que ilumina la clave de esta monografía y la pone oportunamente en relación con la problemática pedagógica actual.

En definitiva, se trata de una obra original y muy recomendable para todo aquel que se interese por la educación y por el futuro de la sociedad. No ignorando la necesidad que tienen de ayuda los maestros y educadores, estas reflexiones salen a su encuentro en aras de servirles de aliento y norte, pues la labor educativa es cada vez más ardua y precaria. En una coyuntura como la nuestra, que con demasiada frecuencia tiende a profesar el relativismo y la superficialidad como su propio credo, es importante que los que se dedican a la docencia encuentren un acicate en su sendero. En ese contexto, esta obra se vuelve provechosa, ya que expone con clarividencia que la educación no puede reducirse a la fría transmisión de determinadas habilidades o capacidades de hacer, ni puede consistir tampoco en satisfacer el deseo de felicidad de las nuevas generaciones colmándolas de objetos de consumo y de gratificaciones efímeras. Ha de tener metas más sublimes y consistentes.

Agradecemos vivamente a la joven editorial “Didáskalos” el servicio prestado sacando a la luz un volumen tan enjundioso como el que nos ocupa. En efecto, los padres y los profesores no son de acero. Sienten fácilmente la tentación de abdicar de sus tareas educativas y de no 
comprender ya ni siquiera cuál es su papel, o mejor, la misión que les ha sido asignada. Pero precisamente así no se brinda a las nuevas generaciones, a chicos y jóvenes, aquello de lo que más precisan. Con respecto a ellos, hemos de ser sembradores de los genuinos valores que dan real consistencia a una vida feraz y en plenitud. En ese horizonte se divisa y enclava benéficamente Dios. La pregunta sobre su lugar en la educación no es, por tanto, ociosa. Ha de responderse y además con tino. Y la respuesta consumada se descubre a la luz de los sacramentos y de la lógica sacramental, que es la de la encarnación. No puede ser de otra manera. Aquí se encierra el tesoro de estas páginas. Los autores del libro lo han individuado y con esta obra quieren compartirlo con los lectores, afirmando sin vacilaciones que una pedagogía cristiana debe asumir este punto de vista: comunicar a Dios a través de los signos de Dios. Ojalá que nunca se olvide el valor y la fecundidad de esta afirmación.

Fernando Chica Arellano

Observador Permanente de la Santa Sede ante la FAO, el FIDA, y el PMA arellano@libero.it 